E.L.U.A., 7, 1991, pp: 117-136.

\title{
DE LOS PREÁMBULOS Y LIMINARES CONSTITUCIONALES COMO METATEXTOS (EN EL TEXTO CONSTITUCIONAL HISPANOAMERICANO) ${ }^{1}$
}

\author{
JUAN PEDRO GÓMEZ \\ (Universidad de Murcia)
}

«Hacer germinar la semilla fecunda de la libertad, destruyendo las preocupaciones vergonzantes con que se le alimentó desde la infancia; establecer el culto de la moral; conservar los nombres y las condiciones que figuran en nuestra historia, asignándoles un lugar en la memoria del tiempo; he aquí la tarea noble, pero vasta y difícil, que nos ha impuesto el amor de la patria.»

ANDRÉS BELLO («El Repertorio Americano»,1826-27)

\section{ENTRAMADO, TEXTURA Y EMBUCLEAMIENTO}

El enfrentamiento entre la realidad antroposocial y el pensamiento político conduce inexorablemente a lo que Edgar Morin denomina «tragedia política» (1983: 504); una tragedia ante la cual sólo el recurso de las «fuerzas vivas» — la fraternidad

\footnotetext{
${ }^{1}$ Este trabajo ha sido realizado en el marco del Proyecto de Investigación PB87-0839 de la D.G.I.C.Y.T. del Ministerio de Educación y Ciencia.
} 
(la revolución) y el amor (la religión)— puede constituir el antídoto adecuado contra la desintegración de la hipercomplejidad social (Ibíd. 504-505).

El ansia de organización humana en el objeto constitucional, el deseo inevitable de enmarcamiento y ahormamiento, se textualiza en torno a toda una serie de «expresiones faro» que cohesionan la textura y reconducen el entramado del pensamiento político de cada pueblo, sometiendo principios y verdades a la acción rígida de la normativa legal y a la vaguedad y ambigüedad de sus caracterizaciones semánticas más profundas.

En el seno de este lenguaje, cuajado de expectativas utópicas, la esperanza actúa como espera de un «bonum futurum» (Pedro Laín, 1957: 279-282). Desde una perspectiva heideggeriana, la esperanza constitucional estaría más en la línea de la auténtica «expectativa» (aguardar la realización de las posibilidades utópicas) que en la de la «espera» de lo esperado; correspondería a las «esperanzas concretas» (spoirs) vs el «estado de esperanza» (espérance) (R. Le Senne, 1955: 249-278; Laín, 1957: 314).

El proyecto constitucional, boceto, esbozo, empresa e intención «a concluir y ejecutar», se concentra en los textos preliminares del programa general con una forma propia, primaria y delimitada de la «espera concreta de un pueblo» inmerso en una territorialidad regional precisa. La «espera constitucional», previa al programa y emanada del propio programa en un proceso genético de embucleamiento, predispone a la co-espera de los destinatarios, disponiendo las lógicas modales en una sucesión estructural jerárquica de creencia («se cree que», lógica doxástica) y de preferencia, deseo o necesidad («se desea que», lógica bulomayeica) antes de concluir en las normativas específicas del objeto deontológico respecto al actante destinatario, sujeto colectivo afectado por los derechos y deberes previstos por la constitución (E. Ramón Trives, 1990: 103-104) y sometido a la lógica deóntica.

La experiencia sobre los estados de espera lleva al enfrentamiento dicotómico de «promesa» $\mathrm{y}$ «amenaza». Y dado que la «experiencia del vacío» (J. M.Kijm) genera inseguridad, el mecanismo liminar tiende a enmarcar el ordenamiento normativo con un orden y rigor esperanzado; un orden beatífico y justiciero contra todos los posibles demonios ajenos al sentimiento popular (A. Fernández Suárez, 1972: 54-56).

El programa utópico se conforma con un «software» gestionado para la eutopía que, si bien puede actualizarse a través de los múltiples enfoques de características políticas distintas, necesita pautas preliminares de ordenamiento sólido; pautas enmarcadas en una textura (Metzeltin, 1988: 24-25) en la que la precomprensión del mundo está condicionada sociocultural e históricamente (Karl-Otto Apel, 1991: 157).

«Esperanza», «libertad», «paz»y «justicia» son axis en torno a los cuales se globalizan los deseos de la realidad humana en el contexto constitucional hispanoamericano, fundamentado en la tradición republicana y coincidente en lo más profundo con puros presupuestos románticos (Jean Franco, 1975: 56). La sugerencia 
retórica, basada en la creencia y en el convencimiento del destinatario, confirma, de forma paralela al discurso político, la modalidad veredictoria (C. López Alonso, 1990: 54), incluyendo en un macroconjunto de verdad-persuasiva las exposiciones, los convencimientos y las creencias, proposiciones preliminares básicas del objeto constitucional.

«En relación con los derechos sociales que gozamos todos los mexicanos, se elevaron a rango constitucional el derecho a ląsalud y los principios básicos de una política de desarrollo rural integral; el derecho a la vivienda; una mejor administración de justicia que garantice en mayor plenitud la seguridad de los ciudadanos en conflicto, sabedores de que la justicia junto con la libertad es el valor supremo de la convivencia social y del derecho» - el subrayado es nuestro-(Presentación de la Constitución Política de los Estados Unidos Mexicanos, 1987: 7).

En el entramado axiológico, y en sus tensiones correspondientes (libertadsometimiento, solidaridad-insolidaridad, igualdad-desigualdad), se plantean los grados de potencia y los perfiles del dominio intensional. Un término como justicia puede emplearse, liminal y subliminalmente, con un valor sémico de /necesidadsocial/y con un grado de contingencia sublimado retóricamente a través de una lógica epistémica desveladora del comento, aparentemente «inorna-to» (Kurt Spang, 1984), pero grave, subido y magnificado por la acción cualificadora.

Al respecto, y muy atinadamente, Hans Kelsen hace referencia a la justicia, puntualizando:

«La justicia es en primer lugar una cualidad posible, pero no necesaria, de un orden social que regula las relaciones mutuas entre los hombres. Sólo secundariamente es una virtud humana, ya que un hombre es justo si su conducta se adecua a las normas de un orden social supuestamente justo» —el subrayado es nuestro— (1991: 35-36).

\section{APROXIMACIÓN ANALÍTICA}

En una aproximación cautelosa al Preámbulo de la Constitución Política de la República de Ecuador, observamos una caracterización frástica-pragmasemántica basada en frases declarativas no responsivas (Metzeltin, 1988: 37-38), reduciéndose la caracterización sintagmática al esquema del actante-sujeto y de las correspondientes proposiciones:

-Sujeto : La República del Ecuador (Actuante/Actante) 


\section{-Proposiciones:}

a. La R. E. tienc orígenes (históricos)

b. La R. E. es fiel a sus orígenes

c. La R. E. está decidida a progresar en la realización de su destino.

d. La R. E. tiene (pertenece a) un pueblo («su»)

e. La R. E. actúa (invoca y organiza) en nombre de su pueblo

f. La R. E. invoca la protección de Dios * Presuposición : La R. E. cree en Dios

g. La R. E. se organiza

A: «La República del Ecuador invoca la protección de Dios»

B: «se organiza fundamentalmente por medio de esta Constitución Política»

A-B : Es una construcción locutoria de nexuación paratáctica, en la que el carácter reflexivo de la segunda rama exocéntrica se ve matizado por una dependencia aspectual semántica «fundamentalmente», modificadora hipotáctica del predicado (Greimas, 1976: 238) «por medio de»/a través de/ esta Constitución Política. Sin embargo, la circunstancialidad «medial» asume el protagonismo actancial de un complemento agente que le otorga relevancia ejecutiva y protagonismo sémico, bajo una estructura sintáctica de pasivización funcional y forma refleja.

Los valores adjetivales relevantes son:

- Cualificación 1a: fidelidad histórica

- Cualificación 2:a decisión de progreso

Desde la palabra «fiel» a la palabra «destino» se constata una endotaxis generalizadora (E. Ramón Trives, 1982: 82-101).

En un proceso de reducción máxima, se puede plantear la simplificación de la constelación integrada por: A-B

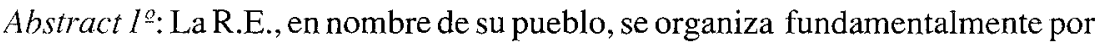
medio de esta Constitución Política

Abstract 2\%: La R. E. se organiza por medio de esta Constitución Política («Valor Macroproposicional»)

Condicionantes:

a. SIENDO fiel a su origen histórico

(Concepto preferencial)

b. ESTANDO DECIDIDA a progresar (Concepto intencional)

c. ACTUANDO en nombre de su pueblo (Concepto posicional)

(Dijk, 1978-1983: 92). 
Respecto a la información connotativa, un conjunto de seis expresiones configuran los correspondientes semas aspectuales o «virtuemas esenciales»

1 a: //República//

$2^{a}: / /$ Fiel a sus orígenes históricos//

3: //Realización de su destino//

$4^{a}$ : //En nombre de su pueblo//

5: //Protección de Dios//

$6^{\mathrm{a}}: / /$ Se organiza por medio de esta Constitución //
$<$ Independencia $>$

$<$ Tradicional $>$

$<$ Progresista $>$

$<$ Democrática $>$

$<$ Religiosa $>$

$<$ Constitucional $>$

Desde un punto de vista de proximidad histórica, aunque el primer texto constitucional fue el «Pacto solemne de Sociedad y Unión entre las provincias que forman el Estado de Quito» (1811), la República Independiente, separándose de la Gran Colombia, no tuvo lugar hasta 1830. Por tanto, se puede entender perfectamente la «juventud romántica» de los conceptos básicos sobre los que se elabora el metatexto, así como su vocación de perennidad y constancia textual.

\section{RELACIONES ACTANCIALES \\ (Modelo greimasiano)}

\section{$1^{\mathfrak{a}}$ Aproximación}

Sujeto Destinador Destinatario Objeto Adyuvante Oponente

La R. E.

Organización

R.E.

El Pueblo del E.

La Constitución

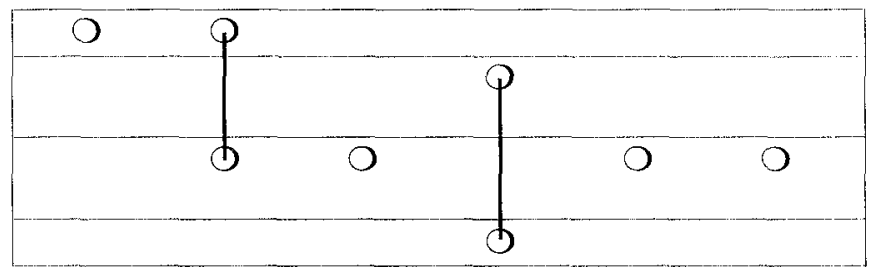

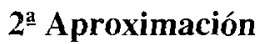

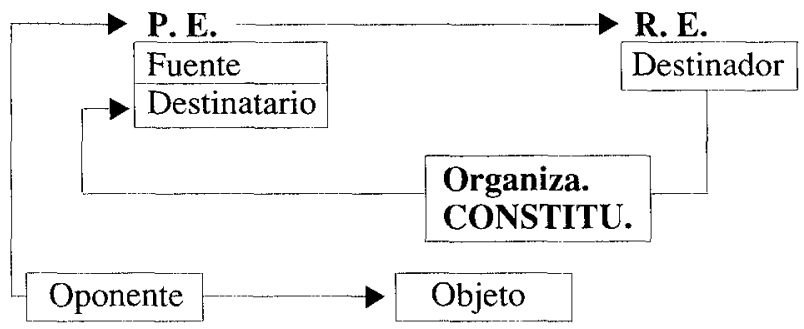


Sujeto-Destinador: República del Ecuador (R. E.)

Destinatario: Pueblo del Ecuador (P. E.)

Objeto: Constitución

Adyuvantes: Los órganos del poder público: Art. $1^{\circ}$ TÍTULO PRELIMINAR Oponentes: Todo lo que vaya contra los principios del TÍTULO PRELIMINAR: colonialismo, discriminación, etc.

\section{APLICACIÓN COSMOLÓGICA CONTEXTUAL:}

\section{ESPACIO EUTÓPICO:}

* El Ecuador es un Estado Soberano... (Párrafo 1, Art.1ํㅜ TITULO PRELIMINAR).

* El territorio es inalienable e irreductible, comprende el de la Real Audiencia de Quito con las modificaciones introducidas por los tratados válidos, las islas adyacentes, el Archipiélago de Colón o Galápagos, el mar territorial, el subsuelo y el espacio

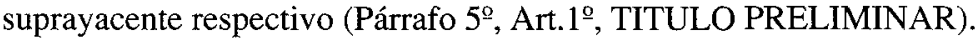

\section{ESPACIO DISTÓPICO:}

A. Histórico: En 1941 tiene lugar el conflicto fronterizo entre Perú y Ecuador. Ecuador perdió $174.000 \mathrm{~km} 2$ de la zona transandina (III Conferencia de Río de Janeiro, 1942).

\section{TEMPORALIDAD TEXTUAL:}

1978 y reforma de 1983, codificación de 1984.

\section{TEMPORALIDAD-MARCO HISTÓRICA:}

1811 Movimiento independentista.

1830 Primer Texto Constitucional propiamente ecuatoriano.

Hasta 1875 Dictadura Constitucional (García Moreno).

1912-1925 Período plutocrático en el que emerge una nueva burguesía.

1933 Elección presidencial de José $M^{\mathrm{a}}$ Velasco Ibarra.

1934 Derrocamiento de Velasco.

1945 Constitución sancionada por Velasco.

1972 Texto constitucional rehabilitado. 


\section{ACCIÓN HISTÓRICA:}
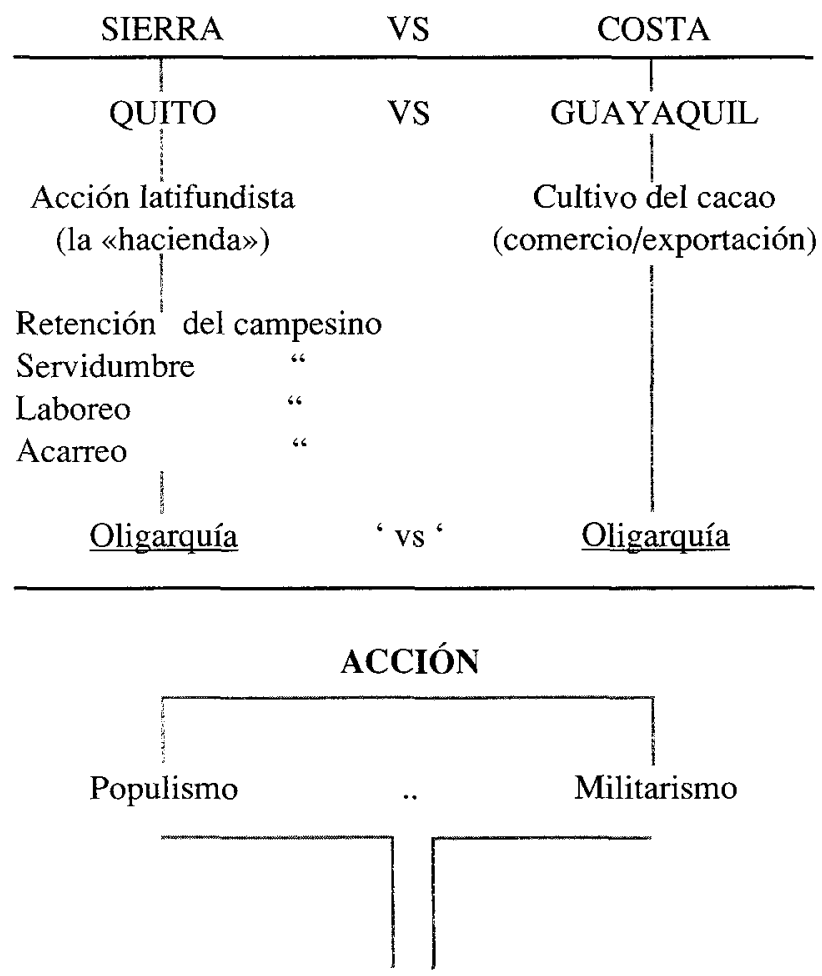

PATERNALISMO

«Velasquismo»

Compactación Obrera Nacional

Concentración de Fuerzas Populares

Partido Nacionalista Revolucionario

\section{ADYUVANTES Y OPONENTES REALES :}

* Fuerzas Armadas (tutelar)

* Movimiento gremio-sindical (conflicto con el Poder Ejecutivo)

* La Iglesia Católica (influencia en la Sierra) 


\section{ACCIÓN ELECTORAL:}

* Permanente: Una vez cada dos años.

\section{ACCIÓN DISCORDANTE:}

* Economía «muy estrecha» y dependiente del petróleo.

* Regionalismo de difícil cohesión.

* Democracia inestable.

En este contexto cosmológico, en el que se realizan las influencias concretas de los campos políticos, militares, religiosos y económicos, las diversas sucesiones históricas «no juegan más que un papel comparable al del contexto extralingüís-tico del discurso» (A. J. Greimas, 1980: 184), que, en este caso, aparece reescrito de forma indiscreta por fuentes diversas. La multiplicidad enunciativa, con sus dependencias causales (Ibíd.: 188), se unifica a través de una síntesis podadora con perfil discreto, dependiendo de factores económicos (estancamiento, deuda externa, desempleo, desigualdad social) (H.Trindade, 1991) muy específicos, desarrollados en las articulaciones textuales posteriores. La acción metatextual y su mecanismo de «embucleaje» tras la pormenorizada exposición y el análisis normativo correspondiente, reconduce al inicio y hace posible la aceptación de toda una serie de verdades «creidas» $\mathrm{y}$ «esperadas» en los vestíbulos constitucionales.

\section{TÍTULO PRELIMINAR}

\section{PREDICACIONES ESENCIALES:}

El Ecuador ES un Estado soberano independiente democrático unitario

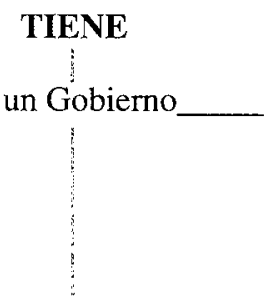

ES presidencial electivo representativo responsable alternativo republicano 


\section{TIENE}

un idioma oficial ES

el castellano

una lengua nativa $\mathbf{E S}$

el quichua

\section{TIENE}

una bandera

un escudo

un himno

SON

simbolos de la Patria

\section{TIENE}

un territorio ES

inalienable

irreductible

\section{TIENE}

una capital ES (su nombre) "Quito»

FUNCIONES primordiales

del Estado SON fortalecer

(la unidad nacional)

(Art.2)

asegurar

(la vigencia de los derechos fundamentales del hombre)

promover

(el progreso económico, social y cultural)

Otras funciones SON proclamar: la paz internacional; la cooperación la igualdad jurídica "

condenar :

la fuerza en conflictos

repudiar :

el despojo bélico 
propugnar :

métodos jurídicos y pacíficos

declarar :

que el Derecho Internacional

es norma de conducta

propugnar :

la comunidad internacional;

la estabilidad y fortalecimiento

de sus organismos; la integración

iberoamericana

(Art.4)

SON

condenar:

toda forma de colonialismo;

toda forma de neocolonialismo;

toda forma de discriminación;

toda forma de segregación racial

reconocer :

el derecho de los pueblos a liberarse de estos sistemas opresivos.

\section{MARCO JUDICATIVO}

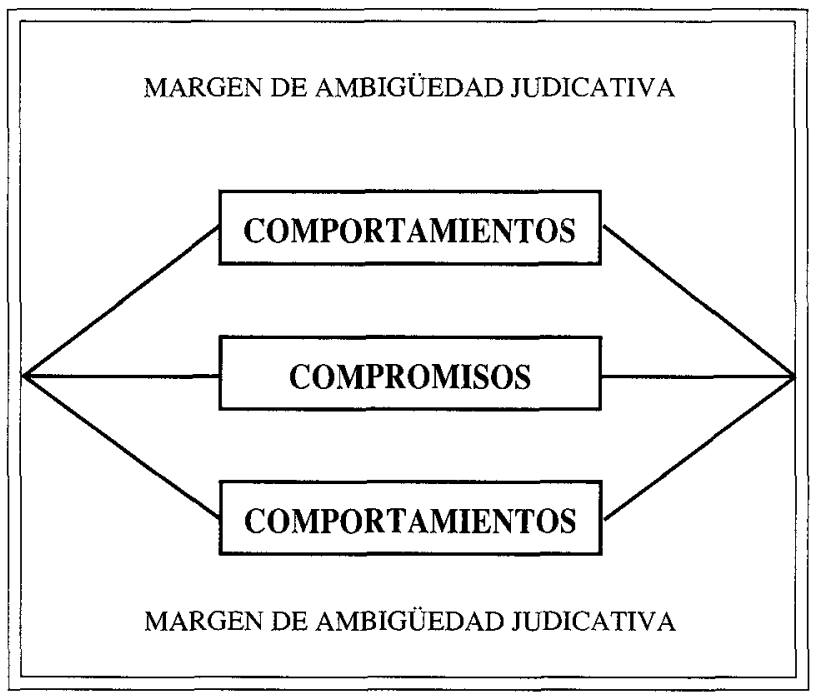




\section{VERBOS CLAVES :}

Según el esquema de J. L. Austin (1990: 195-212), las manifestaciones verbales: promover, proclamar, propugnar, declarar, reconocer, condenary repudiar, ofrecen interrelación de acciones verbales judicativas, compromisorias y comportativas.
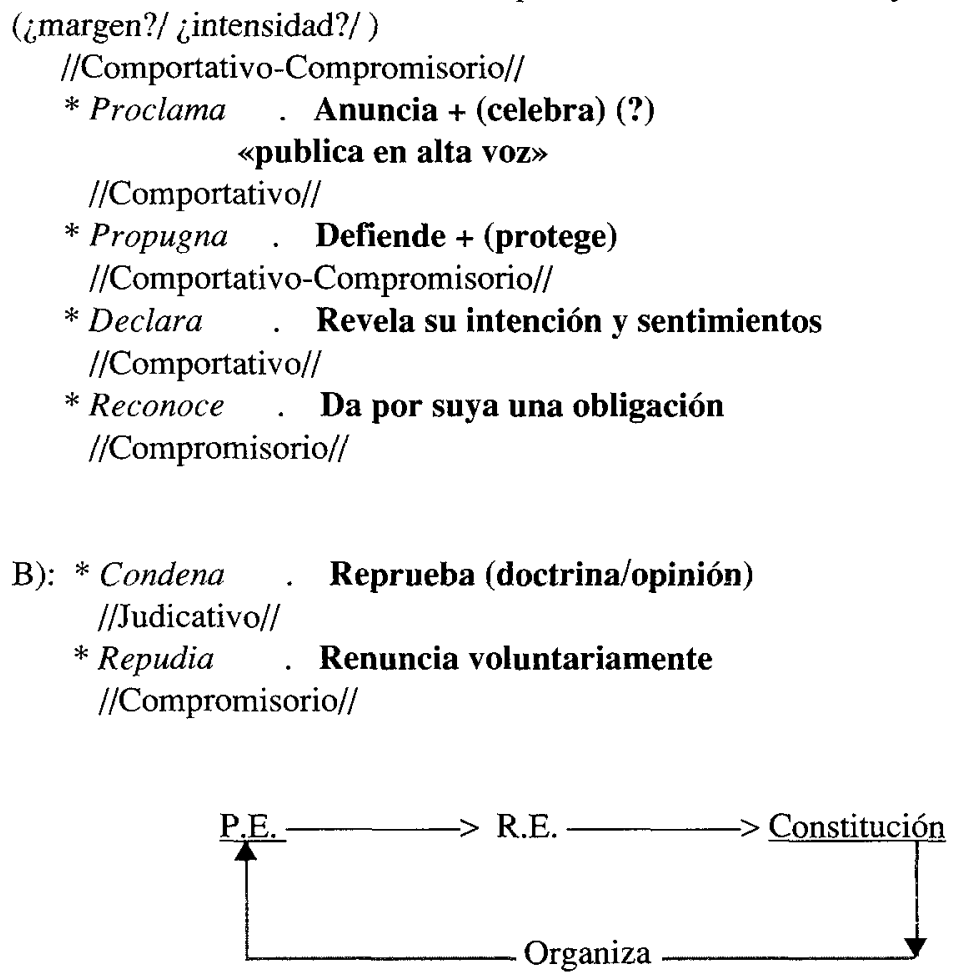

La organización flexible conlleva ambigüedad, abstracción y vaguedad en la recepción, pudiéndose manifestar la acción comportativa de forma eutópica y distópica, mientras que la acción compromisoria lleva siempre a la utopía.

El texto constitucional, emanado del pueblo, mantiene su acción informativa en el conjunto cultural, como un fluido constante que se recupera, reorganiza y realimenta por dos caminos distintos: a) por el mecanismo de «feed-back» y de reforma recogido en el TÍTULO II, Art. 143; b) por el de su propio e inmanente mecanismo utópico-compromisorio, en proceso perlocutivo incontrolable (carácter filosóficosemántico). 


\section{SEGUNDA APROXIMACIÓN : LAS CREENCIAS}

En el Preámbulo de la Constitución Política del Perú, se observa una artificiosa relación al poder constituyente a través de la invocación protectora de Dios y del ejercicio de la potestad soberana. Las causaciones verbales, subrayadas tipográficamente con mayúsculas-CREYENTES,DECIDIDOS, CONVENCIDOS, CONSCIENTES, ANIMADOS, EVOCANDO-, presentan una clara función pragmática que brinda información sobre el contexto: razones, mo-tivos e intenciones, que, como consecuencia, llevan a la decisión: «Nosotros... HEMOS VENIDO EN SANCIONAR Y PROMULGAR,... la presente CONSTITUCIÓN POLÍTICA DEL PERÚ» (1979: 4), verdadero «abstract temático» y macroestructura máxima preambular. La significación progresiva terminativa, tras las construcciones circunstantes temporales precedentes respecto a la acción final (Gili Gaya, 1961: 201 ), tiene un acusado sentido modal y un valor causal:

$\begin{array}{ll}* \text { Porque } & \text { somos creyentes (creemos) } \\ \text { Puesto que } & \text { estamos decididos } \\ \text { Ya que } & \text { estamos convencidos } \\ & \text { somos conscientes } \\ & \text { estamos animados }\end{array}$

Única y solamente se sanciona y promulga la Constitución en base a las acciones, decisiones y evocaciones anteriormente expuestas.

\section{Proposiciones doxásticas:}

\section{Creencias de exposición directa o explícitas} (CREYENTES:):

Construcciones frásticas exocéntricas y seriadas:

* -primacía de la persona humana -todos los hombres son iguales en dignidad -todos los hombres tienen derechos de validez universal -esos derechos son anteriores y superiores al Estado

* -el trabajo es deber y derecho de los hombres -el trabajo representa la base del bienestar nacional

* -la justicia es valor primario de la vida comunitaria -el ordenamiento social se basa en el bien común -el ordenamiento social se basa en la solidaridad humana 


\section{Creencias de expresión indirecta o implícitas}

A. -Se puede crear una sociedad justa, libre y culta

al -Esa sociedad puede ser sin explotador y sin explotados

a2 -Esa sociedad puede estar exenta de discriminación por razones de sexo, raza, credo o condición social

a3 -Esa sociedad tendrá una economía al servicio del hombre y no al revés a4 -Esa sociedad estará abierta a formas superiores de convivencia

a5 -Esa sociedad será apta para aprovechar el influjo de la revolución científica, tecnológica, económica y social

a6 -Esa revolución transforma el mundo

A la reflexión realizada sobre la justicia (supra) habría que añadir, de forma muy especial y por la gran importancia que en estos momentos históricos está teniendo, una consideración muy precisa sobre el poder manipulador de la ciencia (Bertrand Russell, 1969: 8) que va desplazando, gradualmente, el aspecto de cultura y conocimiento.

La utilización de expresiones como «revolución científica» y «revolución tecnológica» puede conllevar semas aspectuales o connotativos de /evolución/, I desarrollo/, /modernidad/ y /bienestar/, pero estos virtuemas positivos pueden enmascarar un virtuema negativo/poder manipulador/, en tanto que los niveles de conocimiento de los destinatarios sean ínfimos o, incluso, no siéndolo, estén desprotegidos frente al discurso autoritario (Daniel Prieto Castillo, 1981).

«Para que una civilización científica sea una buena civilización, es necesario que el aumento de civilización vaya acompañado de un aumento de sabiduría. Entiendo por sabiduría una concepción justa de los fines de la vida. Esto es algo que la ciencia por sí misma no proporciona» —el subrayado es nuestro-(B. Russell, 1969: 9).

Pese a la buena fe de Russell, lingüísticamente nos volvemos a encontrar con las limitaciones semánticas que pueden ayudar a una realidad empobrecida. Tanto la expresión «sabiduría» como la expresión «justa», en la frase anteriormente subrayada, nos remiten en el contex to constitucional hispanoamericano a una servidumbre y a una dependencia de muy diverso grado. Sólo la vaguedad semio-intensional (V. Iturralde, 1989: 32-34) permite una ligera conexión entre la penumbra lingüística y lo inaccesible del concepto en sus múltiples aplicaciones éticas, filosóficas, sociales y políticas concretas en la realidad. 


\section{B. -El Estado podrá ser democrático}

b1 -El Estado se puede basar en la voluntad popular y en su libre y popular y en su libre y periódica consulta

b2 -El Estado democrático puede garantizar la plena vigencia de los derechos humanos

b3 -El E. d. puede garantizar la independencia de la República

b4 -El E. d. puede garantizar la unidad de la República

b5 -El E. d. puede garantizar la dignidad creadora del trabajo

b6 -El E. d. puede garantizar la participación de todos en el disfrute de la riqueza

b7 -El E. d. puede garantizar la cancelación del subdesarrollo

b8 -El E. d. puede garantizar la cancelación de la injusticia

b9 -El E. d. puede garantizar el sometimiento de los gobernantes a la Constitución y a la ley

b10 -El E. d. puede garantizar el sometimiento de los gobernados a la Constitución y a la ley

b11 -El E. d. puede garantizar la efectiva responsabilidad de quienes ejercen función pública

C. -Es necesario impulsar la integración de los pueblos latinoamericanos

D. -Es necesario afirmar la independencia de los pueblos latinoamericanos (contra todo imperialismo)

E. - Todo imperialismo es negativo y condenable

F. - Todos los hombres son hermanos

f1 -La violencia hay que excluirla

G. - Se puede consolidar la personalidad histórica de la Patria

g1 -La personalidad histórica de la Patria es síntesis de valores egregios

g2 -Esos valores son los que le han dado nacimiento

g3 -PATRIA = hija de valores egregios

g4 -El patrimonio cultural existe

g5 -El patrimonio cultural es importante o bueno

g6 - Hay que defender el patrimonio cultural

H. - Hay recursos naturales

hl -Los recursos naturales son buenos

h2 -Hay que asegurar el dominio de los recursos

h3 -Hay que asegurar la preservación de los recursos 
I. -Grandeza del pasado autóctono

Grandeza:

- justiciera (general)

. función cultural del virreinato

- gesta de los libertadores, desde Túpac Amaru a San Martín y Bolívar

. Sánchez Carrión, ilustre fundador de la República

i1 -El pueblo realizó un largo combate

i2 -El combate fue para alcanzar un régimen de libertad

i3 -El combate fue para alcanzar un régimen de justicia

$* * * * * * * * *$

En base a las creencias rastreables en los umbrales de la Constitución del Perú, se puede constatar también la presencia de una serie de recurrencias nucleares de carácter metatextual concreto:

* PREÁMBULO : «CREYENTES en la primacía...»

Ampliación: TÍTULO I, CAPÍTULO I (DE LA PERSONA)

* PREÁMBULO : «-Que la familia es célula...»

Ampliación: TÍTULO I, CAPÍTULO II (DE LA FAMILIA)

* PREÁMBULO : «-Que el trabajo es...»

Ampliación: TÍTULO I, CAPÍTULO V (DEL TRABAJO)

* PREÁMBULO : «-Que la justicia es...»

Ampliación: Conjunto de la totalidad de los titulares

* PREÁMBULO : «DECIDIDOS a promover...» (sociedad justa, libre y culta) Ampliación: Conjunto general + TÍTULO I, CAPÍTULO III (DE LA

SEGURIDAD SOCIAL,SALUD Y BIENESTAR); TÍTULO I, CAPÍTULO I (DE LA PERSONA), CAPI. III (DE LA SEGURIDAD SOCIAL), CAPI.IV (DE LA EDUCACIÓN,LA CIENCIA Y LA CULTURA), CAPITULOV (DEL TRABAJO); TÍTULOIIICAPÍTULO I (DEL RÉGIMEN ECONÓMICO: Principios generales) 
* PREÁMBULO : «DECIDIDOS así mismo...»

Ampliación TÍTULO II (DEL ESTADO Y LA NACIÓN); TÍTULO III (DEL RÉGIMEN ECONÓMICO); TÍTULO IV (DE LA ESTRUCTURA DEL ESTADO).

* PREÁMBULO : «CONVENCIDOS de la necesidad ...» Ampliación: TÍTULO II, CAPÍTULO IV (DE LA INTEGRACIÓN)

* PREÁMBULO : «ANIMADOS por el propósito...» Ampliación: TÍTULO III, CAPÍTULO II (DE LOS RECURSOS NATURALES).

Los textos preliminares, como «comunicados» introductorios que son, tienen la función de preparar el camino al/del hipertexto inmediato posterior; texto allanado por el hilo conductor de una recurrencia continua sobre valoraciones inducidas previamente por las creencias asumidas del sujeto representante del actante destinatario. Se establece entonces un ciclo especular de autoconformación, en el que se encuadra la semiosis de la realidad social (Veron, 1987: 126).

La tipología especial y contradictoria del texto constitucional, fundamentalmente teórico, pero de efectos jurídicos performativos (L. Núñez Ladevéze, 1977: 118), impone la racionalidad metajurídica sobre la lógica jurídica.

El mecanismo de embucleaje, además de hacer posible la aceptación de «creencias» y «esperanzas» en el vestíbulo constitucional, favorece la conversión del objeto constitucional, induciendo a la transformación metamórfica del texto-constitucionalconcreto.

Prolepsis y Analepsis justifican cada realidad extra-lingüística en las construcciones textuales a las que remiten, haciendo de las correspondencias y de las ampliaciones verdaderas manifestaciones de equilibrio y de racionalidad; una racionalidad jurídica, verificadora de la cohesión interna del lenguaje ordinario en el que se inscribe el texto constitucional.

La acción de la prolepsis, «flash-forward» de principios fundamentales, «predispone» a la aceptación de intereses generales a partir de las verificaciones de existencia y creencia. Por otra parte, el positivismo preambular puede verse reforzado, como en el caso de la Constitución peruana, por técnicas o recursos de fundamento experiencial o histórico. Las posibles prohibiciones, las prescripciones y los valores negativos emanados del macrocontexto histórico del país quedan en estado de ocultamiento, bajo la cobertura invisible de la supresión, y sólo los aspectos evocados, extraídos de la grandeza histórica asumida y estereotipada, confirman, en forma modal-causativa, las disposiciones constitucionales del texto subsiguiente basadas en los principios complejos de libertad, justicia y cultura: 
EVOCANDO las realizaciones justicieras de nuestro pasado autóctono; la fusión cultural y humana cumplida durante el virreinato; la gesta de los Libertadores de América que inició en el Perú Túpac Amaru y aquí culminaron San Martín y Bolívar; así como las sombras ilustres de Sánchez Carrión, fundador de la República, y de todos nuestros próceres, héroes y luchadores sociales, y el largo combate del pueblo por alcanzar un régimen de libertad y justicia. HEMOS VENIDO EN SANCIONAR Y PROMULGAR, como en efecto sanciona-mos y promulgamos, la presente CONSTITUCIÓN POLÍTICA DEL PERÚ. (1979: 4).

Es discutible, pero en todo caso atractiva, la teoría de que el arte otorga existencia y credibilidad a los personajes históricos, pero sólo el mito puede otorgar sentido de continuidad frente a la tradición. «La herencia del mito consiste en heredar valores impuestos por aquél. La coherencia en la convivencia humana requiere, por tanto, que la autoridad de la tradición se irradie como tal, pero no porque hubiese sido antes reconocida como buena tradición» (Leszek Kolakowski, 1990: 19). El significado de los procesos históricos y el sentido de los acontecimientos son valores suprahistóricos, míticamente independientes y sobreimpuestos a los fundamentos de derecho. Los acontecimientos mitificados o los héroes elevados a la categoría de mito superan la lógica del derecho en favor de la permanencia existencial de los valores, resultando de especial interés la vaguedad semántica (W.P. Alston, 1980: 125-135) inmanente a los soportes míticos axiales. Los mitos léxicos «libertad» $y$ «justicia» se resisten a ser limitados semánticamente, lo que les permite adecuarse a héroes concretos y a situaciones históricas específicas. Qué duda cabe que el «héroe-dehoy», el personaje histórico positivo filtrado por la tradición, ha alcanzado el grado de valor tras un proceso de pugna, oposición y violencia contra otro-posible-mitohistórico; mito de referente inexistente /Y/o, en algunos casos, «anti-héroe» cargado de valores semánticos indeseables y tabuados en la región.

Los mitos léxicos, formulados en los preámbulos y liminares constitucionales, no están obligados ni subordinados a la lógica del derecho pragmático, sino que, por su carácter proyectivo, eutópico y utópico, aseguran «patterns» de comportamiento en los receptores del desarrollo legal-constitucional. Qué duda cabe que la utilidad semántica del mito está relacionada con las necesidades, siendo las necesidades sociales, filosóficas y religiosas las mejores y más fuertes potenciadoras del mito.

Una postura de clarificación conceptual frente al «definiendum» mítico conduce a una cuasi-explicación significativa de tipo genético y operacional, pero en modo alguno genérica ni específica.

La expresión «libertad» se encuentra definida básicamente por el DRAE como / facultad.../,/estado.../,/prerrogativa.../,/condición.../,/exención.../y/licencia.../; por otra parte, el lexema «justicia», según el mismo DRAE, presenta las acepciones fundamentales de/virtud.../,/atributo.../,/derecho.../y/conjunto de todas las virtudes/ . Las concreciones en sintagmas y contextos determinados abundan en la entropía 
sémica, con un aumento manifiesto de sentidos en las diversas manifestaciones lineales y en las reagrupaciones sémicas de cada texto. El aumento de los límites del conjunto conlleva alejamiento centrífugo y distorsión semio-sinonímica respecto a las acepciones básicas. Desde el <permiso otorgado> de la «libertad de conciencia» al $<$ sentido negativo e indeseable $>$ del $\ll$ desenfreno, contravención y desorden de las buenas costumbres», se produce una verdadera nebulosa sémica en el semema correspondiente. Sin embargo, la expresión mítica, el mito léxico, reduce su especificidad sémica en favor de un incremento de los semas asociativos o connotativos, fuertemente cohesionados en lo que se podría denominar «esfera de totalidad»o «ansia de voluntad totalitaria» con tendencia unidireccional al arquetipo.

En la traslación del significado mítico-social de épocas antiguas y estables a la época actual, todo radica en el individuo frente al grupo (J. Campbell,1972: 341) y, aunque «la conciencia ya no puede inventar, ni siquiera predecir, un símbolo efectivo que prediga o controle el sueño de la noche» (Idem.: 343), todavía la palabra mítica, sometida a los valores de la experiencia individual, puede esgrimir el valor metafísico instrumental de sacrificadora y redentora del «yo». «Justicia»y «libertad», palabras claves, se actualizan de forma realmente auténtica en el vestíbulo y preámbulo de la ley, remitiendo a una especie de ídolo esperanzador afincado en ellas mismas, antes que a un referente externo catalogable y delimitable sígnicamente.

Los estados de injusticia y de carencia de libertad que sufren ciertas sociedades, desde la perspectiva particular de otras sociedades distintas, pueden ofrecer verdaderas gamas de interpretaciones en cantidad y calidad, según sea el espacio cosmológico desde el cual se enjuicie y según sea la ideosincrasia y la «Weltanschauung» de la mente enjuiciadora. Los deberes, las buenas costumbres y la subordinación, respecto a la «libertad», así como la voluntad divina, el derecho-razón, la pena y la regulación de la igualdad o proporción entre las cosas, respecto a la «justicia», son significaciones de aplicación muy indefinida.

La mediación lingüística en las formulaciones míticas conlleva intensionalmente potenciales emocionales, genéricos en la historia colectiva y asimiladores de todas las posibles significaciones otorgadas en la experiencia cotidiana.

La penuria de estos términos y su controlada aplicación en contextos específicos, ya sean textos de tono elevado o sublime, en discursos espontáneos y pasionales o, incluso, en situaciones de carácter demagógico, siempre liberados de la verificación racional, les hace aparecer con una fuerza trascendente que arrastra a la conciencia de forma persuasiva (B. Badura,1979: 53).

Semejante potencia, desde un punto de vista eminentemente pragmático, convierte estas expresiones míticas del campo de la semántica social, en verdaderos puentes o «hooks» de conexión entre la pequeña parcela de evocación privada y el área inabarcable de la utopía colectiva. 


\section{Referencias bibliográficas}

ALSTON, William P. (1980): Filosofia del lenguaje, Alianza Universidad, $2^{2}$ ed., Madrid.

APEL, Karl-Otto (1991): Teoría de la verdad yética del discurso, Paidós, Barcelona. AUSTIN, J.L. (1990): Cómo hacer cosas con las palabras, Paidós, 3르 reim., Barcelona. BADURA, Bernhard (1979): Sociología de la comunicación, Ariel, Barcelona.

CAMPBELL, Joseph (1972): El héroe de lasmil caras. Psicoanálisis del mito, Fondo de Cultura Económica, $1^{\mathrm{a}}$ reim., México.

Constitución Política del Perú (1979), Ministerio de Justicia \& Compañía Peruana de Teléfonos, Lima.

Constitución Política de la República de Ecuador (1979), reproducción de la reforma de 1983 (registro Oficial, n569) y codificación de 1984 (Registro oficial $\mathbf{n}^{\mathrm{a}}$ 763, 12 de junio).

Constitución Política de los Estados Unidos Mexicanos (1987), Secretaría de Gobernación, México.

DIJK, Teun A. van (1978-1983): La Ciencia del Texto, Paidós, Comunicación, Barcelona.

DRAE (1984), Diccionario de la Lengua española, Espasa-Calpe, $20^{a}$ edición, Tomo II, Madrid.

FERNÁNDEZ SUÁREZ, Alvaro (1972): «Utopía y Torre de Babel», en ElUrogallo, 14 , Madrid.

FRANCO, Jean (1975): Historia de la literatura hispanoamericana, Ariel, Barcelona. GILIGAYA, S.(1973): Curso Superior de Sintaxis Española, Vox, $11^{21}$ ed., Barcelona. GREIMAS, A. J. (1976): Semántica Estructural, Gredos, $2^{a}$ reim., Madrid.

GREIMAS, A. J. (1980): Semiótica y Ciencias Sociales, Fragua, Madrid.

ITURRALDESESMA, Victoria(1989):Lenguajelegal y Sistema jurírico. Cuestiones relativas a la aplicación de la ley. Tecnos, Madrid.

KELSEN, Hans (1991): ¿Qué es Justicia?, Ariel, Barcelona.

KOLAKOWSKI, Leszek (1990): La presencia del mito, Cátedra, Madrid.

LAÍN ENTRALGO, Pedro (1957): La Espera y la Esperanza, Revista de Occidente, Madrid.

LESENNE, R. (1955): «Introductionà la description de l'espérance», en La découverte de Dieu, París.

LÓPEZ ALONSO, Covadonga (1990): «La Argumentación en el Discurso Político», en Investigaciones Semióticas III, Retórica y Lenguajes, Actas del III Simposio Internacional, vol. II, Asociación Española de Semiótica, Madrid. 
METZELTIN, Miguel (1988): Lingüística textual y análisis de textos hispánicos, Secretariado de Publicaciones e Intercambio Científico, Universidad de Murcia.

MORIN, Edgar (1983): El Método II. La vida de la Vida, Cátedra, Madrid.

NUÑEZ LADEVÉZE, Luis (1977): Lenguaje jurídico y ciencia social, Akal Editor. PRIETOCASTILLO, Daniel (1981): Discurso autoritario y comunicación alternativa, Edicol, Colec.Comunicación, 1'ªreim., México.

RAMÓN TRIVES, E. (1982): Estudios Sintáctico-Semánticos del Español-I-La Dinámica Interoracional, Godoy, Murcia.

RAMÓN TRIVES, E. (1990) : «Aspectos semio-lingüísticos del Texto Constitucional Hispanoamericano», en Voz y Letra, $I$, Revista de Filología, Arco/ Libros, Madrid.

RUSSELL, Bertrand (1969): La perspectiva científica, Ariel, Barcelona.

SPANG, Kurt (1984): Fundamentos de retórica, Universidad de Navarra, $1^{\text {a }}$ reim., Pamplona.

TRINDADE, Hélgio (1991): «Elementos presidenciales y transición política en América latina», en La hora de la democracia, Rev. Internacional de Ciencias Sociales, UNESCO.

VERÓN, E. (1987): La semiosis social, Gedisa, Barcelona. 